\title{
The extent of late gadolinium enhancement can be assessed fast and reproducible using semi- quantitative method in patients with hypertrophic cardiomyopathy
}

Frank Gommans ${ }^{1 *}$, Jeannette Bakker ${ }^{3}$, Etienne Cramer ${ }^{1}$, Maurice J Kurvers ${ }^{2}$, Freek W Verheugt ${ }^{1}$, Marc A Brouwer ${ }^{1}$, Marcel Kofflard ${ }^{2}$

From 16th Annual SCMR Scientific Sessions

San Francisco, CA, USA. 31 January - 3 February 2013

\section{Background}

In hypertrophic cardiomyopathy (HCM) assessment of late gadolinium enhancement (LGE) is increasingly important as LGE has been demonstrated to be an adverse prognosticator. Manual delineation of LGE after visual assessment is labour-intensive. Automatic quantification is limited by its dependence on signal/noise ratio and varying definition of LGE. Our aim is to assess inter-individual agreement of a fast semi-quantitative method based on visual assessment for quantification of LGE in HCM, which is feasible for daily clinical practice.

\section{Methods}

We included 88 patients (60 clinical HCM patients, 28 subclinical HCM mutation carriers); age $48.9 \pm 15.0$ years; 42 males. MRI was performed with $3 \mathrm{D}$-contrastenhanced inversion recovery imaging. Each segment of the AHA-17-segment model was scored to determine extent of LGE $(0=$ no LGE, $1=1-25 \%, 2=26-50 \%, 3=51$ $75 \%, 4=76-100 \%)$ by two independent observers. The score was summed and converted to a percentage of the maximum possible score (68) to estimate the extent of LGE relative to LV mass. LGE results were compared to assess inter-individual agreement on the presence and extent of LGE in all subjects and in subjects that were LGE positive according to both observers, respectively.

\section{Results}

The agreement on the presence and the extent of LGE was good (kappa $=0.768$ and $r=0.861, p<0.001$, respectively). Regarding presence of LGE: in 10 of 88 patients (11\%) there was disagreement on the presence of LGE. In 8 of these 10 subjects the proportion of LV mass with LGE was scored between $1 / 68$ and $3 / 68$ by the other observer (i.e. $<5 \%$ ). Regarding extent of LGE: a difference in extent of LGE was reported in 42 of 43 patients with LGE. However, the size of the difference between observers was less than 3 points (i.e. $<5 \%$ ) in $75 \%$ of subjects $(32 / 43)$. A difference of $>6$ points (i.e. $>10 \%$ ) was only seen in $4 / 43$ patients $(10 \%)$.

\section{Conclusions}

There is good agreement between two independent observers on the presence and extent of LGE in HCM using the fast semi-quantitative method. We suggest that this method based on visual assessment might be incorporated in future studies and clinical practice as it substantially speeds up the analysis.

\section{Funding}

None.

\section{Author details}

${ }^{1}$ Cardiology, Radboud University Nijmegen Medical Centre, Nijmegen, Netherlands. 'Cardiology, Albert Schweitzer Hospital, Dordrecht, Netherlands. ${ }^{3}$ Radiology, Albert Schweitzer Hospital, Dordrecht, Netherlands. 
doi:10.1186/1532-429X-15-S1-E118

Cite this article as: Gommans et al:: The extent of late gadolinium enhancement can be assessed fast and reproducible using semiquantitative method in patients with hypertrophic cardiomyopathy. Journal of Cardiovascular Magnetic Resonance 2013 15(Suppl 1):E118.

Submit your next manuscript to BioMed Central and take full advantage of:

- Convenient online submission

- Thorough peer review

- No space constraints or color figure charges

- Immediate publication on acceptance

- Inclusion in PubMed, CAS, Scopus and Google Scholar

- Research which is freely available for redistribution

Submit your manuscript at www.biomedcentral.com/submit 